\title{
The role of intrinsic dynamics and noise for neural encoding and synchronization
}

\author{
Christian Finke $^{1 *}$, Hans A Braun², Ulrike Feudel ${ }^{1}$ \\ From Twentieth Annual Computational Neuroscience Meeting: CNS*2011 \\ Stockholm, Sweden. 23-28 July 2011
}

Transitions from tonic firing (single spikes) to burst discharges (impulse groups) play an important role for neuronal information processing (sensory encoding, information binding) and are closely associated with neuronal synchronization in many physiological processes (hormone release, sleep-wake cycles) as well as in disease (Parkinson, epilepsy). Synchronization is typically considered to depend on the network connectivity. The intrinsic dynamics of individual neurons are mostly neglected. However, in computer simulations we have seen that transitions from tonic firing to burst discharges can significantly facilitate synchronization without any changes of the coupling strength $[1,2]$. Thereby, it is not really surprising that periodically bursting neurons synchronize. The more interesting question is why the same neurons need much higher coupling strengths for synchronization when they are operating in a likewise periodic but tonic firing mode. Remarkably, the tonic firing mode also appeared to be much more sensitive to noise [3] which, in terms of phase space, can be related to deviations of the trajectories in the vicinity of a saddle point [4]. Our study shall help to understand under which conditions these particular features appear.

We have used a simplified Hodgkin-Huxley-type approach to implement different types of model neurons for the examination of their synchronization properties especially in the tonic firing mode. Starting point was a four-dimensional model neuron for spike-generation with subthreshold oscillations which can be tuned to a diversity of impulse pattern [5] and which exhibits the above described features. For comparison, we have

\footnotetext{
* Correspondence: christian.finke@uni-oldenburg.de

${ }^{1}$ Institute for Chemistry and Biology of the Marine Environment, Carl von Ossietzky Univ. of Oldenburg, Germany

Full list of author information is available at the end of the article
}

examined HH-type model neurons without subthreshold oscillations but pacemaker properties.

When two identical, periodically firing neurons in the same dynamic state are connected via gap junctions (diffusive coupling) it should be expected that they are synchronizing at infinitely low coupling strengths in all periodically firing regimes. Indeed, this is the case in the examined model neurons - with only one exception as mentioned above. The subthreshold currents of the oscillatory subsystem, although not recognisable in the tonic firing regime, are introducing a dynamic instability on which the particular noise sensitivity is built up and which likewise prevents immediate synchronization. The input from neighboured neurons can be considered as a disturbance which rather induces random phase fluctuations than in-phase synchronisation.

The interdependencies between subthreshold and spike generating currents and their different time scales seem to be the necessary conditions for this behaviour but only the overlapping of their activation range, bringing the trajectories close to a saddle point, provides sufficient conditions.

\section{Conclusion}

The model mimics quite well the experimentally observed impulse pattern and their relations to neuronal synchronisation, indicating that alterations of the neurons' intrinsic dynamics can play an important role for synchronization also in real physiological systems. It is a particular challenge is to examine such phenomena in experimental studies. From the computational point of view, it needs to be analysed whether these noise and synchronisation effects are specific features of the here examined model [5] or general properties of model neurons which can be tuned from bursting to a pacemaker-like tonic firing mode. Such studies also can help

(C) 2011 Finke et al; licensee BioMed Central Ltd. This is an open access article distributed under the terms of the Creative Commons 
to further elucidate from what kind of dynamics these specific features arise and, physiologically most important, under which conditions they can be expected.

\section{Acknowledgments}

Supported by grant FE 359/10 of the German Science Foundation (DFG) and the E.U. through the Network of Excellence BioSim contract No LSHB-CT-

2004-005137

\section{Author details}

1 Institute for Chemistry and Biology of the Marine Environment, Carl von

Ossietzky Univ. of Oldenburg, Germany. ${ }^{2}$ Neurodynamics Group, Institute of

Physiology, Philipps University of Marburg, Germany.

Published: 18 July 2011

\section{References}

1. Postnova S, Voigt K, Braun HA: Neural Synchronization at Tonic-toBursting Transitions. J Biol. Physics 2007, 33:129-143.

2. Postnova S, Finke C, Jin W, Schneider H, Braun HA: A computational study of the interdependencies between neuronal impulse pattern, noise effects and synchronization. J Physiol Paris 2010, 104:176-189.

3. Finke C, Vollmer J, Postnova S, Braun HA: Propagation effects of current and conductance noise in a model neuron with subthreshold oscillations. Mathematical Biosciences 2008, 214:109-121.

4. Finke C, Postnova S, Rosa E, Freund JA, Huber MT, Voigt K, Moss F, Braun HA, Feudel U: Noisy activation kinetics induces bursting in the Huber-Braun neuron model. Europ Phys J Special Topics 2010, 187:199-203.

5. Braun HA, Voigt K, Huber MT: Oscillations, Resonances and Noise: Basis of Flexible Neuronal Pattern Generation. Biosystems 2003, 71:39-50.

doi:10.1186/1471-2202-12-S1-P109

Cite this article as: Finke et al:: The role of intrinsic dynamics and noise for neural encoding and synchronization. BMC Neuroscience 201112 (Suppl 1):P109.

\section{Submit your next manuscript to BioMed Central and take full advantage of:}

- Convenient online submission

- Thorough peer review

- No space constraints or color figure charges

- Immediate publication on acceptance

- Inclusion in PubMed, CAS, Scopus and Google Scholar

- Research which is freely available for redistribution 